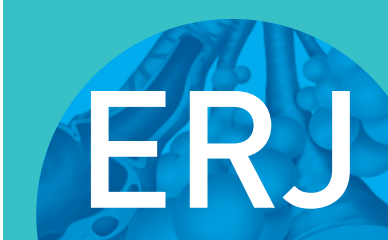

open research

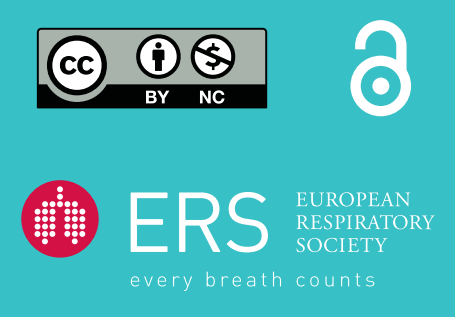

\section{Continuous positive airway pressure adherence declines with age in elderly obstructive sleep apnoea patients}

\section{To the Editor:}

Obstructive sleep apnoea (OSA) is an important public health problem with an estimated prevalence of $5-15 \%$ in the general population. This increases with age, peaking at $20-25 \%$ in individuals aged $>65$ years. This high prevalence of OSA in the elderly will presumably continue to grow as a consequence of the increasing longevity of the general population [1]. It is therefore not surprising that there is a steady increase in the percentage of patients $>65$ years of age referred to sleep units for suspicion of OSA and subsequently receiving continuous positive airway pressure (CPAP) therapy. One Spanish study that analysed 51000 sleep studies from 16 sleep units revealed that one in four of these studies was performed in individuals aged $\geqslant 65$ years, and that $69 \%$ of these were eventually treated with CPAP [2]. Despite this high prevalence, there is little information about long-term CPAP adherence in this population, especially in the very elderly (aged $>80$ years). We thus aimed to analyse the relationship between age at diagnosis and long-term CPAP adherence, in a large cohort of OSA patients aged $\geqslant 65$ years who had been prescribed CPAP treatment.

We analysed a cohort of 939 consecutive patients aged $\geqslant 65$ years referred for suspicion of OSA to two Spanish sleep units. We have previously reported the effect of CPAP treatment on cardiovascular outcomes in this cohort. Accordingly, the methodological aspects of the study, as well as the baseline features of this population, have been described in detail elsewhere [3]. Every subject underwent a sleep test, either simplified respiratory polygraphy or conventional polysomnography. In those patients in whom OSA was diagnosed, CPAP therapy was prescribed according to current Spanish guidelines [4]. A total of 698 patients $(74.3 \%)$ were diagnosed with OSA and offered CPAP treatment, and they are the subject of this study. The study was approved by the Ethics Committee of each participating centre. All the participants provided informed signed consent.

Once CPAP had been started, patients were reviewed at 3-6-monthly intervals during the first year and every 12 months thereafter. During these appointments, patients were encouraged to use the device, while any side-effects were addressed. Information on CPAP adherence was supplied by the domiciliary therapy provider and CPAP use was objectively assessed by reading the device's time-counter. The data included in this study were the average cumulative CPAP compliance, from the start of treatment to the end of follow-up.

The cohort had a mean \pm SD age of $70.9 \pm 26.4$ years (range $65-91$ years; $64.7 \%$ males). For the current study, the elderly patients were stratified into four age groups, namely $65-69$ years $(n=429 ; 45.7 \%), 70-74$ years $(n=317 ; 33.8 \%), 75-79$ years $(n=155 ; 16.5 \%)$ and $\geqslant 80$ years $(n=38 ; 4 \%)$. The mean \pm SD apnoea-hypopnoea index (AHI) was $42.3 \pm 27.4$ events. $\mathrm{h}^{-1}$ with a mean \pm SD Epworth Sleepiness Scale (ESS) score of 10.6 \pm 4.9 . The mean \pm SD CPAP was $9.9 \pm 2.7 \mathrm{cmH}_{2} \mathrm{O}$. Patients were followed for a median of 69 months (interquartile range $49-87$ months). At the end of follow-up, $69.7 \%$ of the patients had good adherence, defined as CPAP use of at least $4 \mathrm{~h} \cdot$ night $^{-1}$. It is striking that fewer patients aged $\geqslant 80$ years were prescribed CPAP, compared to those aged $65-79$ years $(53 \%$ versus $75 \% ; \mathrm{p}=0.001)$. Although there were no significant differences between the groups in terms of AHI $(\mathrm{p}=0.24)$, body mass index (BMI; $\mathrm{p}=0.5)$, ESS score

@ERSpublications

In the very elderly, the indication and prescription of continuous positive airway pressure should be individualised http://ow.ly/NHfN30nC6VK

Cite this article as: Martinez-Garcia MA, Valero-Sánchez I, Reyes-Nuñez N, et al. Continuous positive airway pressure adherence declines with age in elderly obstructive sleep apnoea patients. ERJ Open Res 2019; 5: 00178-2018 [https://doi.org/10.1183/23120541.00178-2018].

Copyright @ERS 2019. This article is open access and distributed under the terms of the Creative Commons Attribution Non-Commercial Licence 4.0. 


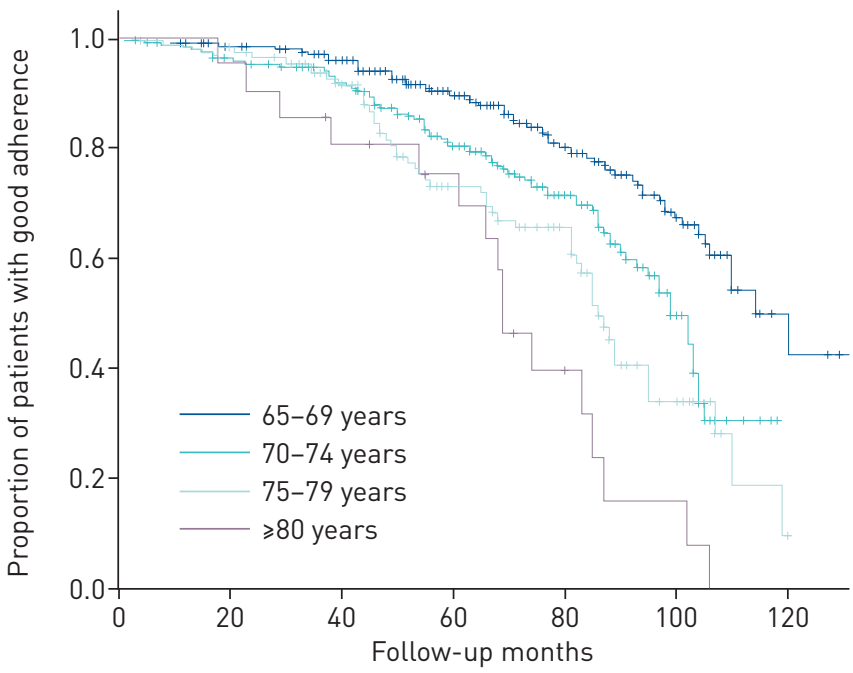

FIGURE 1 Kaplan-Meier curves according to age group for the proportion of patients with a good continuous positive airway pressure adherence (at least $4 \mathrm{~h} \cdot \mathrm{day}^{-1}$ ) during follow-up. Log-rank $\mathrm{p}<0.05$ for any comparison between two curves.

$(\mathrm{p}=0.12)$ and CPAP $(\mathrm{p}=0.8)$, adherence to CPAP showed a progressive decrease with advancing age. Mean \pm SD CPAP use in h.night ${ }^{-1}$ was $5.2 \pm 2.6,4.6 \pm 3.0,3.8 \pm 2.9$ and $2.9 \pm 1.7$ for the age groups of $65-69$, $70-74,75-79$ and $\geqslant 80$ years, respectively ( $p$ for trend $<0.001$ ). Similarly, the percentage of patients with at least $4 \mathrm{~h} \cdot$ night $^{-1}$ of CPAP usage also decreased as the groups aged: $78 \%, 67.5 \%$, 56\% and $23.8 \%$, respectively ( $\mathrm{p}$ for trend $<0.001$ ). Figure 1 shows the Kaplan-Meier survival curves for each age group.

Most OSA guidelines and international consensus emphasise that age should not, in itself, be a deterrent against treatment with CPAP $[4,5]$. In fact, two recent randomised controlled trials enrolling elderly OSA patients aged $>65-70$ years and followed up for 3-12 months achieved improvements in quality of life and showed adequate adherence rates [6,7]. CPAP adherence in the very elderly, however, is as yet unknown.

The present study, comprising OSA patients aged $\geqslant 65$ years, shows a linear and progressive decline in CPAP adherence with increasing age that peaks beyond 75 years. This poorer adherence occurs even though CPAP indication in very elderly patients is probably more selective than in younger cases, given that for similar AHI, BMI and ESS scores, the percentage of prescribed CPAP is significantly lower (especially in patients $\geqslant 80$ years) than in patients aged $65-74$ years. Thus, in the age group of $75-79$ years the average use was $3.8 \mathrm{~h} \cdot$ night $^{-1}$, dropping to $<3 \mathrm{~h} \cdot$ night $^{-1}$ in patients who started CPAP aged $\geqslant 80$ years. The low adherence observed in OSA patients starting CPAP after the age of 75 years probably has many causes, including a greater number of comorbidities (especially stroke, which has been associated with very poor adherence), neurocognitive impairment, difficulties with self-fitting the mask caused by osteoarthritis, lack of family support and decrease in the quality or quantity of sleep. All these factors are associated with advanced age [8]. Our results do not concur with those reported by other researchers who have shown similar, or even better, adherence rates in the elderly compared to younger OSA patients treated with CPAP. These disparate findings may be attributable to different baseline characteristics of the patients, particularly the scarcity of very old patients (aged $>75-80$ years) in these cohorts, as well as the lack of specific analyses of this group $[9,10]$.

Our results show that CPAP adherence decreases as age increases, and it is particularly poor in patients aged $>75$ years. This raises the question as to whether this poor compliance is intrinsically associated with some of the aforementioned traits of the elderly and would therefore be difficult to overcome, or whether it could be improved with appropriate strategies. Since the diagnosis of OSA in very elderly subjects is expected to increase steadily in the next years, future studies should investigate whether tailored strategies and close monitoring could improve CPAP adherence in very elderly OSA patients, and whether this approach is cost-effective in terms of clinical and cardiovascular outcomes. Some approaches on this topic have been discussed in the consensus published by the International Geriatric Sleep Medicine Task Force on principles of practice parameters for the treatment of OSA in the elderly and frail elderly [5]. Until such approaches have been shown to be beneficial, the prescription of CPAP in elderly OSA patients aged $>75$ years (and more particularly $\geqslant 80$ years) should be individualised.

Among the limitations of our study are the low percentage of patients in whom CPAP therapy was started beyond the age of 80 years (only 4\%). This reduces the study's statistical power, but this percentage is 
similar to that of other series [11]. Furthermore, data on adherence were not available at each appointment and we can thus only analyse adherence at the end of the follow-up, without tracing its evolution over the course of the follow-up.

In conclusion, our results in a large cohort of elderly OSA patients treated with CPAP with a long-term follow-up suggest that adherence rates decline with age and are particularly poor in patients aged $>75$ years. Thus, in the very elderly, the indication and prescription of CPAP should be individualised and, when prescribed, closely monitored to address noncompliance and tolerance.

Miguel Angel Martinez-Garcia ${ }^{1}$, Irene Valero-Sánchez ${ }^{2}$, Nuria Reyes-Nuñez ${ }^{3}$, Grace Oscullo $\oplus^{1}$, Alberto Garcia-Ortega ${ }^{1}$, Jose Daniel Gómez-Olivas ${ }^{1}$ and Francisco Campos-Rodriguez ${ }^{3,4}$

${ }^{1}$ Pneumology Dept, Hospital Universitario y Politécnico la Fe, Valencia, Spain. ${ }^{2}$ Respiratory Support and Sleep Centre, Royal Papworth Hospital, Papworth Everard, UK. ${ }^{3}$ Respiratory Dept, Hospital Universitario Valme, Instituto de Biomedicina de Sevilla (IBIS), Seville, Spain. ${ }^{4}$ Centro de Investigación Biomédica en Red de Enfermedades Respiratorias (CIBERES), Madrid, Spain.

Correspondence: Miguel Angel Martinez-Garcia, Pneumology Service, Hospital Universitario y Politécnico la Fe, 46015 Valencia, Spain. E-mail: mianmartinezgarcia@gmail.com

Received: Oct 102018 | Accepted after revision: Jan 072019

Author contributions: M.A. Martinez-Garcia, I. Valero-Sánchez and F. Campos-Rodriguez contributed to study design and writing. N. Reyes-Nuñez, G. Oscullo, A. Garcia-Ortega and J.D. Gómez-Olivas contributed to data acquisition and data interpretation. All the authors approved the final draft of the manuscript.

Conflict of interest: None declared.

\section{References}

1 Peppard PE, Young T, Barnet JH, et al. Increased prevalence of sleep-disordered breathing in adults. Am J Epidemiol 2013; 177: 1006-1014.

2 Martínez-García MÁ, Amilibia J, Chiner E, et al. Apnea del sueño en individuos de edad avanzada. Actividad asistencial (2002-2008) [Sleep apnoea in elderly individuals: care activity in Spain (2002-2008)]. Arch Bronconeumol 2010; 46: 502-507.

3 Martínez-García MA, Campos-Rodríguez F, Catalán-Serra P, et al. Cardiovascular mortality in obstructive sleep apnea in the elderly: role of long-term continuous positive airway pressure treatment: a prospective observational study. Am J Respir Crit Care Med 2012; 186: 909-916.

4 Martínez-García MA, Durán-Cantolla J, Montserrat JM. El sindrome de apneas-hipopneas durante el sueño en edades avanzadas [Sleep apnea-hypopnea syndrome in the elderly]. Arch Bronconeumol 2010; 46: 479-488.

5 Netzer NC, Ancoli-Israel S, Bliwise DL, et al. Principles of practice parameters for the treatment of sleep disordered breathing in the elderly and frail elderly: the consensus of the International Geriatric Sleep Medicine Task Force. Eur Respir J 2016; 48: 992-1018.

6 Martínez-García MÁ, Chiner E, Hernández L, et al. Obstructive sleep apnoea in the elderly: role of continuous positive airway pressure treatment. Eur Respir J 2015; 46: 142-151.

7 McMillan A, Bratton DJ, Faria R, et al. Continuous positive airway pressure in older people with obstructive sleep apnoea syndrome (PREDICT): a 12-month, multicentre, randomised trial. Lancet Respir Med 2014; 2: 804-812.

8 Weaver TE, Chasens ER. Continuous positive airway pressure treatment for sleep apnea in older adults. Sleep Med Rev 2007; 11: 99-111.

9 Yang MC, Lin CY, Lan CC, et al. Factors affecting CPAP acceptance in elderly patients with obstructive sleep apnea in Taiwan. Respir Care 2013; 58: 1504-1513.

10 Woehrle H, Graml A, Weinreich G. Age- and gender-dependent adherence with continuous positive airway pressure therapy. Sleep Med 2011; 12: 1034-1036.

11 López-Padilla D, Alonso-Moralejo R, Martínez-García MÁ, et al. Continuous positive airway pressure and survival of very elderly persons with moderate to severe obstructive sleep apnea. Sleep Med 2016; 19: 23-29. 